\title{
DESAFIOS E PERSPECTIVAS NA RECUPERAÇÃO DE ÁREAS DE EXTRAÇÃO DE ARGILA NO CERRADO
}

\author{
Ralph Barbosa Rodrigues Alves ${ }^{(a)}$, Idelvone Mendes Ferreira ${ }^{(b)}$, Thaís Abadia Barbosa Rodrigues \\ Alves Figueiredo ${ }^{(\mathrm{c})}$, Rosirlene Lopes Da Cruz ${ }^{(\mathrm{d})}$ \\ (a) Mestrando em Geografia / UFG - Regional Catalão, E-mail: ralphpmgo@ hotmail.com \\ (b) Professor Dr. em Geografia / UFG - Regional Catalão, E-mail: idelvoneufg@ gmail.com \\ (c) Graduação em Agronomia / UFU - Uberlândia, E-mail: thaisabadia@ yahoo.com.br \\ (d) Mestranda em Geografia / UFG - Regional Catalão, E-mail: rosirlenelopezdacruz@gmail.com
}

\section{EIXO: SOLOS E PAISAGENS}

\begin{abstract}
Resumo
Empreendimentos que envolvem a remoção do solo causam profundas modificações no equilíbrio ambiental dos ecossistemas, sendo importante o teste de hipóteses que modifique as características químicas e físicas do subsolo remanescente. O Brasil possui uma das maiores biodiversidades, e grande parte dela encontra-se no bioma Cerrado, que possui suas especificidades ambientais. Havendo alterações nesse bioma, no caso a remoção de argila, é necessário a revisão dos sistemas de recomposição do extrato orgânico para a formação de um camada superficial de solo, pois o uso de mecanismos que proporcionem melhorias nas características químicas e físicas, como a semeadura de gramíneas e leguminosas (culturas que possuem menor exigência nutricional), são capazes de se desenvolverem em ambiente desfavorável e produz biomassa, proporcionando a cobertura orgânica do subsolo exposto e condições favoráveis ao desenvolvimento de outras espécies (nativas), mais exigentes nutricionalmente.
\end{abstract}

Palavras chave: Cerrado. Equilíbrio ambiental. Adubação verde.

\section{Introdução}

A produção de energia é essencial para manutenção do sistema econômico vigente, no caso o capitalista, pois a energia é mercadoria e o seu consumo é determinado e direcionado por lógicas do mercado, sendo necessária a produção de energia elétrica, o que leva à necessidade da construção de Usinas Hidrelétricas e/ou outro modelo de produção, como a energia a parti dos bioenergéticos como a cana-de-açúcar.

Contudo para as construções de barragens para a geração de energia hidrelétrica é necessário um grande volume de argila, utilizada para sustentar as rochas no processo de enrocamento do eixo da barragem, que geralmente é extraído de áreas próximas às futuras instalações da hidrelétrica, com isso surgem as "áreas de empréstimo". No Brasil nas décadas anteriores a 1980, não se previa a recuperação destas áreas de extração de argila, tendo sido estabelecido os processos de recuperação pela Resolução CONAMA 001/1986, que estabeleceu a elaboração dos Estudos de Impactos Ambientais e o Relatório de Impactos ao Meio Ambiente - EIA/RIMA. 
Nesse contexto de ausência da legislação, geralmente o subsolo remanescente ficava exposto e sujeito a intensos processos de impactos ambientais, com destaque para uma maior intensidade de processos erosivos causados pela associação: subsolo exposto - índice de precipitação - declividade.

Atividades humanas que necessitam da utilização das camadas do solo, a exemplo da retirada de argila (área de empréstimo) e mineração, devem preservar, armazenar e retornar o horizonte orgânico superficial do solo, que é chamado de "topsoil" ou solo superficial (camada superior, mais externa do solo, em geral entre 0 a $20 \mathrm{~cm}$ de profundidade), onde é encontrado a mais alta concentração de matéria orgânica, microrganismos vivos e atividades biológicas diversas (HALL et al., 2010). Quando esse procedimento não é possível, um novo solo superficial deve ser criado para servir como substrato para o desenvolvimento da vegetação futura, considerando os aspectos físico-químicos da área e os demais processos inerentes à formação do solo.

Para construção de barragens de terra é utilizado argila retirada de áreas próximas aos projetos a serem construídos, o que até os anos 1980 não previam qualquer projeto para recuperação ambiental dessas áreas após sua exploração. No entanto após 1980 os projetos de recuperação das áreas de empréstimo tinham como objetivo cessar os processos erosivos lineares e implantar uma vegetação nativa que proporcione uma paisagem mais próxima à encontrada no Bioma Cerrado.

Porém, as paisagens encontradas em áreas com projetos de recuperação, não se aproxima das paisagens encontradas no Bioma Cerrado, pois em um planejamento de recuperação de áreas degradadas, o grande desafio a ser alcançado é o estabelecimento de um horizonte A para o solo, para que, a partir daí, o processo de formação do solo seja catalisado pela biosfera, podendo surgir outros horizontes, conforme o condicionamento natural. Desse modo, interfere-se em um ou mais fatores de formação do solo, numa tentativa de acelerar sua gênese, considerando, conforme Jeny (1941 apud MONIZ, 1972) que esse processo é composto pela interação entre o material de origem, as condições do relevo, a ação dos agentes do clima, a ação biológica dos organismos vivos e a ação do tempo.

Diante dos fatos, novos processos de intervenção visando o aprimoramento de técnicas para a estruturação do solo devem ser empregados na recuperação de áreas utilizadas para retirada de argila que tenha como objetivo uma possível recuperação paisagística para as mesmas.

\section{O bioma Cerrado}

Cerrado é um domínio fitogeográfico, com bioma do tipo Savana, sendo o segundo maior Bioma que ocorre no Brasil, com uma diversidade vegetacional que engloba a forma campestre aberta, como os Campos Limpos, até formas relativamente densas, florestais, como o Cerradão, entre esses extremos 
fisionômicos, há uma gama de formas intermediárias, com fisionomia de Savana, como os Campos Sujos, os Campos Cerrado, mas as fitopaisagens predominantes são o Cerrado Típico, o Cerradão e a Vereda (FERREIRA, 2003).

Ferreira (2003) também relata que:

As primeiras citações e descrições sobre as características do Cerrado foram feitas pelos Bandeirantes que adentravam os "sertões" do Brasil à procura de minerais preciosos e índios para escravizarem. Nessas viagens, geralmente, eram acompanhados por algum estudioso responsável pela descrição e relato da viagem. Posteriormente, os viajantes estrangeiros passaram a incursionar pelas paisagens brasileiras, coletando espécies e fazendo descrições detalhadas dos aspectos paisagísticos que compunham o espaço brasileiro. (FERREIRA, 2003, p. 39).

A expansão da fronteira agrícola brasileira levou à redução dessas áreas de cobertura original e a altas taxas de extinção de espécies, sendo que até os dias atuais, é continua a destruição dos ecossistemas que constituem o Cerrado. Machado et al. (2004), em estudo utilizando imagens do satélite MODIS do ano de 2002, concluiu que 54,9\% do Cerrado já foi desmatado ou transformado pela ação humana. Nesse sentido, Tristão e Mendes (2015) relatam as causas e efeitos da degradação do Cerrado, além das dificuldades para a interversão favorável à preservação desse Bioma:

A expansão produtiva em áreas de Cerrado tem ocasionado consequências ambientais, e vem deixando de considerar à influência que este exerce sobre os demais ecossistemas nacionais, o papel fundamental desse bioma para reposição hídrica, e a sua diversidade biológica. Dessa forma, as comunidades biológicas são alteradas de forma contundente, sendo que o fator econômico e a desvalorização da paisagem do Cerrado dificultam que ocorram maiores intervenções a favor da preservação desse bioma. (TRISTÃO; MENDES, 2015, p. 13).

O Brasil possui uma das maiores biodiversidades mundial, e grande parte dela encontra-se no bioma Cerrado. O Cerrado abrange cerca de 200 milhões de hectares (22\% do território nacional), compreendendo uma larga variedade de fisionomias específicas que dominam o Centro-Oeste Brasileiro, como as Matas de Galerias que se desenvolvem ao longo dos rios e córregos e Matas Secas que medram sobre solos quimicamente mais ricos, bem como vegetação de transição nas bordas com outros biomas. (MENDONÇA et al. 1998; UNESCO, 2001).

\subsection{A geração de Energia e o impacto ambiental}

A geração de energia esta envolvida diretamente com a história do desenvolvimento socioeconômico da humanidade, como exemplos temos a revolução industrial, com destaque a introdução no sistema produtivo da máquina a vapor e, posteriormente, o motor a combustão. Atualmente, o acentuado uso de fontes energéticas não renováveis, como os de origem mineral e nuclear associado ao alto padrão de consumo de energia, criou uma série de questionamentos ambientais, destacando-se os poluentes emitidos com a queima de combustíveis fósseis que ultrapassam as fronteiras mundiais, alterando a concentração 
dos gases responsáveis pelo efeito estufa, principalmente o Dióxido de Carbono $\left(\mathrm{CO}_{2}\right)$ (CECHIN, 2010), causando, no contexto mundial, a elevação da temperatura.

Desse modo, se fosse cientificamente possível fazer uma relação custo-benefício de todo o processo civilizatório, a conclusão seria provavelmente pessimista, em que os problemas advindos do mundo moderno ultrapassariam em grande escala os benefícios produzidos pela sociedade pós-industrial (PHILIPPI JÚNIOR; SILVEIRA, 2004).

Na busca da humanidade por uma energia limpa e renovável, o potencial hidráulico dos cursos d'água é destacado, e a conversão desta energia potencial em energia elétrica depende da construção das usinas hidrelétricas, onde, com a utilização de turbinas movimentadas pela água e ligadas a alternadores, ocorre a conversão da energia potencial em energia mecânica e posteriormente em energia elétrica. Nesse contexto, Bossoi e Guazelli (2004), ressaltam, ainda, que o uso da água para geração de energia é muito desenvolvido no Brasil, uma vez que detém o terceiro lugar na produção de energia hidrelétrica, com 10\% da produção mundial, atrás do Canadá e dos Estados Unidos, cada um com 14\% da produção mundial.

As usinas hidrelétricas, com o objetivo de obter o uso do maior potencial energético são, muitas vezes, construídas em locais distantes dos centros consumidores, sendo então transmitida por fios condutores até as cidades, ocorrendo assim à elevação dos gastos com o transporte dessa energia, o que também dificulta a percepção, por parte de diferentes grupos sociais, quanto aos diferentes impactos ambientais e sociais causados com a construção das usinas hidrelétricas, visto que os benefícios da produção da energia elétrica são de fácil reconhecimento da população humana (ALVIM FILHO, 2009).

Mesmo sendo uma energia renovável e não ocorrer a emissão de poluentes, a energia elétrica gerada por usinas hidrelétricas são responsáveis por inúmeros danos sociais, como a relocação da população de pequenos agricultores, indígenas, ribeirinhos, entre outras, e impactos ambientais como alteração do curso e do regime hídrico dos rios, inundação de extensas áreas de vegetação nativa, extinção de espécies da biota, alterações do microclima, dentre outros. Nesse sentido, Bossoi e Guazelli (2004), afirmam que o uso da água para a produção de energia elétrica não modifica sua qualidade; no entanto, altera o ambiente e a vida aquática, visto que um ambiente que era lótico torna-se lêntico.

\subsection{A recuperação de áreas degradadas}

A recuperação de áreas degradadas começou a ter um destaque maior a partir das décadas de 1960 e 1970, principalmente devido à pressão dos órgãos ambientais e da sociedade organizada, culminando pelo estabelecimento da Resolução do Conselho Nacional do Meio Ambiente (CONAMA) 001/1986, que estabeleceu normas e critérios para os projetos de intervenção ambiental no Brasil, culminando na obrigatoriedade da apresentação e execução dos Planos de Recuperação de Áreas Degradadas (PRADE) e 
os Estudos de Impacto Ambiental e Relatórios de Impactos ao Meio Ambiente (EIA-RIMAs) e uma legislação subsequente cada vez mais especifica. A escassez de informações ainda dificulta a sua efetiva implantação, sendo fatores limitantes a ausência de plantas adaptadas a condições inóspitas ao crescimento vegetal em solos degradados e um planejamento socioeconômico e ambiental de uso das espécies de interesse para sua recuperação na região da degradação. Além disso, verifica-se ainda a falta de conhecimento quanto à interação das diferentes espécies potenciais com diferentes tipos de solo e materiais e sua ciclagem de nutrientes (SPERÂNDIO, 2013).

A implantação de uma cobertura vegetal sobre superfícies de áreas degradadas é a medida mais comum de recuperação, mas requer a construção de um ambiente edáfico que seja compatível com as espécies vegetais a serem utilizadas (CORRÊA; BENTO, 2010). Nesse cenário, as leguminosas se destacam como espécies potenciais para inserção em ambientes com pouca ou nenhuma resiliência, por possuírem alta deposição de serrapilheira e, principalmente, pela fixação biológica de Nitrogênio atmosférico no solo (LONGO et al., 2011).

Para uma eficiente revegetação e utilização de novas práticas e formas de manejo para a recuperação de áreas degradadas, é necessária a intensificação de pesquisas que contemplem a interação dos conhecimentos das propriedades químicas, físicas e biológicas do solo, da fenologia e da ciclagem de nutrientes das espécies vegetais, sendo que, por falta de conhecimento, é usual assumir que protegendo a vegetação está se resguardando todos os seres vivos que aí vivem, toda a sua vida ou pelo menos parte de seu ciclo de vida. Essa é a posição possível com o conhecimento disponível, mas ela não garante o sucesso do controle e da gestão de áreas verdes. Com a evolução do conhecimento será permitido um controle mais seguro com bases científicas e monitoramento mais adequado do meio ambiente (BONONI, 2004). Empreendimentos que envolvem a remoção do solo, e deixam o substrato litólico exposto, envolvem profundas modificações no equilíbrio ambiental dos ecossistemas, podendo demandar várias dezenas de anos para adquirir níveis de equilíbrio homeostático incipiente. Os substratos remanescentes, além de estarem desprovidos de atributos físicos e químicos, que permitam a colonização vegetal espontânea, apresentam-se suscetíveis a ação dos processos erosivos. "A crescente conscientização ambiental da sociedade organizada, aliada às ações dos ambientalistas, tem acelerado a busca de novas "equações ambientais", que objetivam a minimização dos impactos socioambientais a um baixo custo" (D'ALTERIO; VALCARCEL, 1996).

A sucessão ecológica é definida por Horn (1974), como sendo um fenômeno que envolve gradativas variações na composição específica e na estrutura das comunidades tróficas, iniciando-se o processo em áreas que, mediante ações perturbatórias ou não, se apresentam disponíveis à colonização de plantas e animais e outros seres vivos, prosseguindo até determinado período onde tais mudanças se tornam lentas, 
sendo o ecossistema resultante designado como clímax. Essas variações são determinadas por mudanças na vegetação, na biota, no solo e no microclima de uma área com o decorrer do tempo.

O uso da cobertura vegetal (medida biológica) como medida mitigadora dos impactos ambientais é uma opção coerente, prática e econômica, embora possa apresentar dificuldades de adaptação inerentes à declividade do terreno e a composição física e química do substrato (D’ALTERIO; VALCARCEL, 1996). Quando se avalia a relação custo/benefício ambiental, o uso de recursos naturais apresenta a melhor relação quando comparados aos demais métodos de recuperação de áreas degradadas (MACHADO et al., 2003). Neste sentido, a implantação de leguminosas lenhosas associadas a microrganismos é uma alternativa para minimizar as perdas de nutrientes por percolação e erosão, alcançar a autossuficiência em nitrogênio através da fixação biológica e obter máxima reciclagem de nutrientes no ambiente (LASTE, 2008).

\subsection{A adubação verde}

Os adubos verdes são obtidos através do cultivo de plantas com características que possibilitam a melhoria em médio e longo prazo de propriedades físico-químicas do solo, redução na competição entre espécies, além do cultivo para fins comerciais os adubos verdes são cultivados para utilização como cobertura morta em áreas com histórico de manejo inadequado do solo. Alguns exemplos de adubos verdes são a Cajanus cajan (feijão guandu), a Crotalaria juncea (crotalária) e o Stylosanthe multilinea (estilozantes). Em Áreas de Proteção Permanente, as APPs, em processos de revegetação, essas espécies podem ser utilizadas em consórcios com espécies arbóreas, pois a busca por novas alternativas, como agregação de valores, cogeração de energia elétrica e novos sistemas de administração, são constates (TEODORO et al., 2011). Os estudos referentes ao uso dos adubos verdes tem demonstrado um grande potencial na recuperação da produtividade do solo e, dentre as diversas leguminosas usadas como adubo verde, a Crotalária mostra-se muito eficiente como produtora de massa vegetal e como fixadora de nitrogênio nos solos. A prática de adubação verde, embora apresente várias vantagens, é pouco utilizada pela maioria dos agricultores, principalmente durante o verão, pois para eles o cultivo de uma espécie de adubo verde não propicia retorno econômico imediato, ou seja, ocupa o espaço de outra cultura de renda (DOURADO et al., 2001). Isto ocorre em função do desconhecimento dos efeitos benéficos das plantas de cobertura nos sistemas de produção. Por outro lado, Skora Neto (1993) sugere que é desejável que a adubação verde seja considerada uma prática economicamente rentável, principalmente para a recomposição de matéria orgânica nos solos. 
A simbiose mutualista planta-bactéria diazotróficas-fungos micorrízicos, adquire a capacidade de incorporar carbono $(\mathrm{C})$ e nitrogênio $(\mathrm{N})$ atmosféricos ao solo, sendo mais eficientes na absorção de nutrientes, tornando as plantas mais tolerantes aos estresses ambientais (FRANCO; BALIERO, 2000).

Vilela (2004), avaliando a exigência nutricional de gramíneas e leguminosas forrageiras, encontrou uma larga variação em relação à exigência e adaptação entre as espécies forrageiras e conclui que entre as leguminosas verifica-se que a Stylosanthes captata é mais tolerante ao alumínio (Al) e menos exigente ao fósforo $(\mathrm{P})$, enquanto a soja perene se apresenta como mais exigente em fósforo e cálcio $(\mathrm{Ca})$ e menos tolerante ao Alumínio e que uma pastagem formada com uma planta mais exigente, como um Panicum $s p$. , terá um período de uso pequeno, se não houver atenção à adubação de manutenção.

A discussão sobre "Qualidade do Solo" intensificou-se no início dos anos 1990, quando a comunidade científica, consciente da importância do solo para a qualidade ambiental, começou a abordar, nas publicações, a preocupação com a degradação dos recursos naturais, a sustentabilidade agrícola e a função do solo nesse contexto (VEZZANI, 2009).

O solo, sem a proteção da sua superfície, sofre grandes perdas, não só de terra, como também de carbono (C) e nitrogênio $(\mathrm{N})$. O carbono orgânico total (COT) é a principal fonte de $\mathrm{N}$ e serve para determinar a qualidade do solo e tem uma importância muito grande na agricultura sustentável. As propriedades físicas, químicas e biológicas do solo são estimadas pela fração orgânica, determinada pelo COT. Em geral, a matéria orgânica do solo contém 58\% de carbono (C). A degradação do solo influi diretamente no teor de N, pois o COT é a principal fonte deste nutriente (BRAGA, 2011).

Dependendo da magnitude do fluxo de carbono propiciado pelo subsistema vegetal, haverá maior ou menor atividade biológica, produção de compostos orgânicos secundários, agregação do solo e aparecimento de outras propriedades emergentes do sistema solo. De modo geral, as propriedades emergentes do ciclo do C no solo (teor de matéria orgânica, agregação, porosidade, infiltração de água, retenção de água, aeração, Capacidade de Troca Catiônica - CTC, balanço de N, dentre outras) melhoram a qualidade do solo (VAN BREEMER, 1993).

A localização geográfica das áreas degradas a serem rescuperadas deve ser considerada, visto que, no bioma Cerrado há espécies que ocorrem somente em solos ácidos, outras são restritas aos solos calcários e outras indiferentes quanto à acidez e/ou fertilidade do solo (RATTER et al., 1977). Assim, Jordan (1987) destaca a proporção de $\mathrm{N}$, Ca e magnésio $(\mathrm{Mg})$ que é encontrado nos troncos das arvores, sendo que esses nutrientes servirão de estoque do ecossistema durante sucessão secundária, reforçando a importância da vegetação na proteção do solo e ciclagem dos nutrientes.

Santos et al. (2001), trabalhando com duas leguminosas (Feijão guandu - Cajanus cajan L. e Siratro Macroptilium atropurpureum L.) e duas gramíneas (Capim-pangola - Digitaria decumbens L. e Capim- 
elefante - Pennisetum purpureum L.) não havendo incorporação da biomassa verificaram pelas análises químicas efetuadas que as culturas melhoraram os teores de nutrientes no solo, promovendo aumento nos teores de carbono orgânico total e na capacidade de troca de cátions, indicando serem viáveis na recuperação de solos degradados, sendo que o Siratro apresentou melhor resposta em relação à CTC e o capim-elefante proporcionou maior acúmulo da manta vegetal sobre o solo.

\section{Considerações finais}

Os estudos referentes ao uso dos adubos verdes com o objetivo de melhorar as características químicas e físicas do solo tem demonstrado um grande potencial, sendo que a Crotalária se destaca por sua eficiência na produção de biomassa e como eficiente fixadora de nitrogênio nos solos. Contudo plantas com baixa exigência nutricional como a Brachiaria $s p$. e Stylosanthes sp. demonstram capacidade de desenvolvimento em ambiente desfavorável, possuem características como alta produção de biomassa e quando utilizadas em conjunto, proporcionam diferenças em suas relações $\mathrm{C} / \mathrm{N}$, além disso, podem ser utilizadas como pastagem, o que torna um meio de recuperação de área degrada com possibilidade de auto manutenção dos custos para a recuperação da área a ser contemplada.

A fertilização mineral e o uso de material orgânico contribuem para a melhoria das características químicas, físicas e biológicas do solo, proporcionando melhores condições para que as espécies possam exercer as funções de produção biológica, e possível sustentabilidade do ambiente, pois em um ambiente desprovido de vegetação, e também de material orgânico não decomposto que proporcione a cobertura do solo, é comum observar a incidência de erosão laminar. Considerando que as áreas de empréstimos, após a extração de suas camadas superficiais, ficam com o subsolo exposto, é comum que seus atributos químicos, físicos e biológicos estejam comprometidas e a interação entre tais características também.

Com isso, o desenvolvimento da biomassa fica comprometido, afetando o volume de cobertura vegetal e também o volume de material orgânico não decomposto, consequentemente será menor o volume de matéria orgânica decomposta, não proporcionando a proteção do subsolo exposto, aumentando, assim, a erosão laminar que em uma reação em cadeia será cada vez maior ao longo dos anos.

\section{Referências}

ALVIM FILHO, A. C. Desafios e perspectivas de P\&D na geração de energia elétrica. Revista Pesquisa e Desenvolvimento da ANEEL - P\&D, Brasília, v.1, n.3, p.12, 2009.

BONONI, V. L. R., Controle ambiental de áreas verdes. In: PHILIPPI JÚNIOR, A., ROMERO, M. A., BRUNA, G. C., Curso de gestão ambiental. Barueri: Manole, 2004. cap. 6, p. 213-255. 


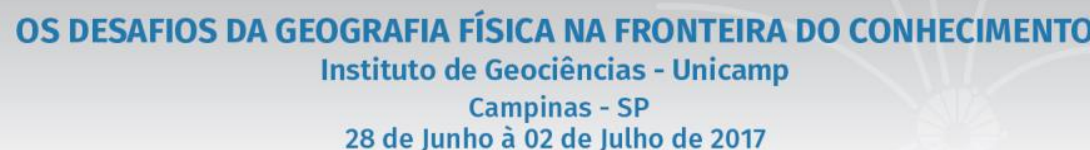

28 de Junho à 02 de Julho de 2017

BOSSOI, L. J., GUAZELLI, M. R., Controle ambiental da água. In: PHILIPPI JÚNIOR, A., ROMERO, M. A., BRUNA, G. C., Curso de gestão ambiental. Barueri: Manole, 2004. cap. 3, p. 51-99.

BRAGA, G. N. M. Carbono Orgânico Total (COT) Determina Qualidade do Solo. Agricultura Sustentável/Meio Ambiente. Disponível em: < http://agronomiacomgismonti. blogspot.com.br/2011/10/carbonoorganico-total-cot-determina.html>. Acesso em: 19 Jan. 2016.

CECHIN, A. A natureza como limite da economia: a contribuição de Nicholas Georgescu-Roegen. São Paulo: Editora Senac, 2010. 264 p.

CORRÊA, R. S.; BENTO, M. A. B. Qualidade do substrato minerado de uma área de empréstimo revegetada no Distrito Federal. Revista Brasileira de Ciência do Solo, Viçosa, v. 34, n. 4, p. 1435-1443, 2010.

D’ALTERIO, C. F. V.; VALCARCEL, R. Medidas fisico-biológicas de recuperação de áreas degradadas: “avaliação das modificações edáficas e fitossociológicas". In: VI JORNADA DE INICIAÇÃ̃O CIENTIFICA. Resumos..., Rio de Janeiro: UFRRJ, 1996 p. 52.

DOURADO, M.C.; SILVA, T.R.B.; BOLONHEZI, A.C. Matéria seca e produção de grãos de Crotalaria juncea L. submetida à poda e adubação fosfatada. In: CONGRESSO DE INICIAÇÃO CIENTÍFICA. Scientia Agricola, v.58, n.2, p.287-293, 2001.

FERREIRA, I. M. O Afogar das veredas: uma análise comparativa espacial e temporal das veredas do Chapadão de Catalão (GO). 2003. 242 f. Tese (doutorado) - Universidade Estadual Paulista, Instituto de Geociências e Ciências Exatas, 2003. Disponível em: <http://hdl.handle.net/11449/104459>. Acesso em: 27 jul. 2016, 09:22:00.

FRANCO, A. A.; BALIERO, F. de C. The Role of biological nitrogen fixation in land reclamation, agroecology and sustainability of tropical agriculture. In: ROCHA-MIRANDA, C.E., (Ed.). Transition to global sustainability: The contribution of brazilian science. Rio de Janeiro: Academia Brasileira de Ciências, p.209-234, 2000 .

HALL, S. L. BARTON, C.D. BASKIN, C.C. Topsoil seed bank of an oak-hickory forest in eastern Kentucky as a restoration tool on surface mines. Restoration Ecology, Washington, v. 18, n. 6, p834-842, 2010.

HORN, H. S. Nutrient cycling in tropical forest ecosystems. Chichester, John Wiley. 1974. 190p.

JORDAN, C. F. Amazonian rainforests: Ecosystem disturbance and recovery. New York, Springer, 1987. 133p.

LASTE, K.C.D. Seleção de estirpes de rizóbio eficientes na fixação biológica de nitrogênio para leguminosas com potencial de uso na recuperação de áreas mineradas. 2008. $23 \mathrm{f}$. Trabalho de Conclusão de Curso (Bacharel em Engenharia Florestal) - Instituto de Florestas, Universidade Federal Rural do Rio de Janeiro. Seropédica, 2008.

LONGO, R. M.; RIBEIRO, A. I.; MELO, W. J. Recuperação de solos degradados na exploração mineral de cassiterita: biomassa microbiana e atividade da desidrogenase. Bragantia, Campinas, v. 70, n. 1, p. 132-138, 2011.

MACHADO, R.B., M.B. RAMOS NETO, P.G.P. PEREIRA, E.F. CALDAS, D.A. GONÇALVES, N.S. SANTOS, K. TABOR E M. STEININGER. Estimativas de perda da área do Cerrado brasileiro. Relatório técnico não publicado. Conservação Internacional, Brasília, DF. 2004.

MACHADO, R. L.; MOREIRA, J. F.; FARIA, S. M. de. Seleção de estirpes de rizóbio para leguminosas com potencial de uso na recuperação de áreas degradadas. In; Congresso Brasileiro de Ciência do Solo, 29., 2003, Ribeirão Preto. Resumos... Botucatu: SBCS, 2003. 4 p. CD ROM.

MENDONÇA, R. C. et al. Flora vascular do Cerrado. In: SANO, S. M.; ALMEIDA, S. P. Cerrado: ambiente e flora. Planaltina: EMBRAPA-CPAC, 556 p. 1998.

MONIZ, A. C. et al. Elementos de pedologia. Rio de Janeiro: LTC, 1972.

PHILIPPI JÚNIOR, A., SILVEIRA, V. F., Saneamento ambiental e ecologia aplicada. In: PHILIPPI JÚNIOR, A., ROMERO, M. A., BRUNA, G. C., Curso de gestão ambiental. Barueri: Manole, 2004. cap. 2, p. 19-52.

RATTER, J. A.; RICHARDS, P.W.; ARGENT, G.; GIFFORD, D. R. Observações adicionais sobre o cerradão de solos mesotróficos no Brasil central. In: Ferri, M. G. (editor) IV Simpósio sobre o cerrado. São Paulo, Editora da Universidade de São Paulo, p 306-316, 1977. 


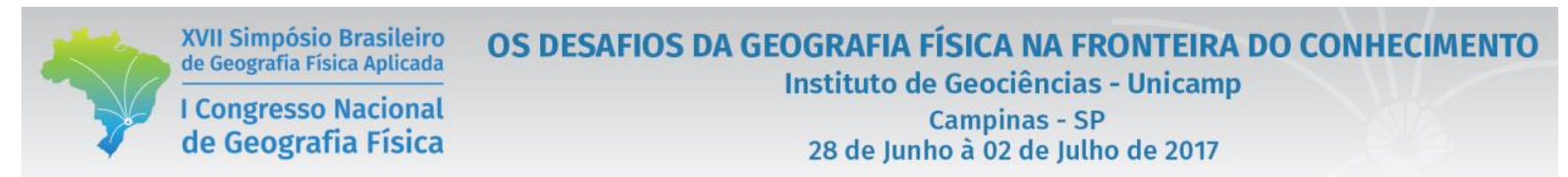

SANTOS, A. C.; SILVA, I. F.; LIMA, J. R. S.; ANDRADE, A. P.; CAVALCANTE, V. R. Gramíneas e leguminosas na recuperação de áreas degradadas: efeito nas características químicas de solo. Revista Brasileira de Ciência do Solo, Viçosa, v. 25, p. 1063-1071, 2001.

SKORA NETO, F. Controle de plantas daninhas através de coberturas verdes consorciadas com milho. Pesquisa Agropecuária Brasileira, v.28, p.1165-1171, 1993.

SPERÂNDIO, H. V. Tephrosia cândida D.C. e Mimosa velloziana Mart: biomassa, serapilheira e fertilidade do solo. 2013. 75f. Dissertação (Mestrado em Ciências Florestais) - Universidade Federal do Espírito Santo, Jerônimo Monteiro, 2013.

TEODORO, R. B.; OliveIRA, F. L.; SILVA, D. M. N.; FÁVERO, C.; QUARESMA, M. A. L. Aspectos agronômicos de leguminosas para adubação verde no Cerrado do Alto Vale do Jequitinhonha. Revista Brasileira de Ciência do Solo, Viçosa, v. 35, n. 2, p. 635-640, 2011.

TRISTÃO, M. C; MENDES, E. DE P. P. Efeitos da conversão vegetacional na estrutura e dinâmica de paisagens do cerrado no município de Goiandira (GO): uma abordagem sob a perspectiva bertrandiana. Espaço em Revista, Catalão, v. 17, n. 1. jan/jun. 2015. Disponível em: <http://www.revistas.ufg.br/espaco/article/view/39272>. Acesso em: 27 jul. 2016.

UNESCO Vegetação no Distrito Federal tempo e espaço. Brasília, 2001. 74 p.

VAN BREEMER, N. Soils as biotic cronstruct favouring net primary productivity. Geoderma, 57:183-211, 1993.

VEZZANI, F. M.; MIELNICZUK, J. Revisão de literatura. Uma visão sobre qualidade do solo. Revista Brasileira de Ciência do Solo, Viçosa, v. 33, p. 743-755, 2009.

VILELA, H., DUARTE VILELA, BARBOSA F.A., BENEDETTI E. Efeito de níveis de adubação de manutenção sobre a produção de pastagem de Panicum maximum e leguminosas em pastejo. Aspectos agronômicos. In: Zootec 2004. Anais... Brasília, 2004. CD. 